\title{
Bioaktivni spojevi u plodu, listu i sjemenci maline (Rubus idaeus L.)
}

\section{Sažetak}

Malina (Rubus idaeus L.) jedna je od voćnih vrsta koje su bogate raznolikim kemijskim spojevima kao što su vitamini, minerali i polifenoli. Polifenoli utječu na senzorna i nutritivna svojstva biljke. Listovi i sjemenke maline, koje su većinom nusprodukt proizvodnje imaju značajan sadržaj polifenola, te bi se zajedno s plodovima mogli više koristiti u ljudskoj prehrani kao alternativni izvor bioaktivnih spojeva. U ovom radu određivani su polifenolni spojevi, te je utvrđen sadržaj flavonoida, antocijana i ukupnih fenola u plodu, sjemenci i listu maline sorte 'Himbo Top'. Najveći maseni udio polifenola imale su sjemenke maline, od kojih je izmjereno najviše flavonoida $(2853,03 \mathrm{mg} / 100 \mathrm{~g}$ svježeg uzorka) $i$ ukupnih fenola (2369,44 mg/100 g svježeg ploda), a najmanji maseni udio polifenola kod maline imali su plodovi. Također, određen je i antioksidacijski kapacitet pomoću DPPH i ABTS metode, te nisu utvrđene značajne razlike u antioksidacijskom kapacitetu između ploda, lista i sjemenke. Pomoću LC-MS metode identificirani su pojedinačni antocijani i flavonoli u plodu maline.

Ključne riječi: Malina (Rubus idaeus L.), sjemenka, list, polifenoli, antioksidacijski kapacitet

\section{Uvod}

Malina je široko uzgajana voćna vrsta te 2017. godine zauzima ukupno 118,219 ha svjetskih površina (FAO, 2019). Crvena malina potječe iz Turske, gdje su još u doba Troje ljudi skupljali plodove samonikle maline u podnožju planine Ida. Prema povijesnim podatcima Palladiusa, rimskog botaničara, malina je domestificirana u 4. stoljeću (Nikolić i sur., 2015). Malina koja pripada skupini jagodastog voća prirodni je izvor bioaktivnih spojeva koji pogodno djeluju na ljudsko zdravlje. Bogata je spojevima kao što su vitamini, minerali te je jedan od najbogatijih izvora prirodnih antioksidacijskih spojeva kao što su polifenoli, posebice antocijani i flavonoli. Maline se najčešće konzumiraju u svježem stanju kada je većina bioaktivnih spojeva još aktivna ili kao prerađevine. Upravo zbog svog kemijskog sastava malina se svrstava u funkcionalno voće. Prema Beekwilderu i sur. (2005) utvrđeno je da malina ima veću antioksidacijsku aktivnost od ostalih istraživanih voćnih vrsta kao npr. jagode, kivija i jabuke, te znatno veću od nekih povrtnih vrsta kao što su brokula i rajčica. Prema Žlabur i sur. (2016) malina ima antioksidacijsku aktivnost veću od $50 \%$ u usporedbi s jagodom. Listovi i sjemenke maline, koje su većinom nusprodukt proizvodnje, su bogati polifenolima, te bi se zajedno s plodovima mogli koristiti u ljudskoj prehrani kao alternativni izvor bioaktivnih spojeva. Listovi maline sadrže fenolne kiseline poput klorogenske, galne, ferulinske, kafeinske te flavonoide poput kvercetina i kempferol-3-O-glukozid (Kratchanova i sur., 2010). U Europi se već stoljećima listovi koriste u prirodnoj medicini za razne poremećaje. Sjemenke malina se najčešće koriste u obliku ulja. Zadnjih godina povećana je potražnja za funkcionalnom hranom te ima vrlo malo podataka o sadržaju bioaktivnih komponenata u sjemenkama i listu malina. 


\section{Materijali i metode}

\section{Uzorci}

$\mathrm{U}$ istraživanju korišteni su plodovi, listovi i sjemenke dvogodišnjih sadnica sorte 'Himbo Top' (Rubus idaeus L.). Himbo-Top ${ }^{\circledR}$ je jesenska sorta selekcionirana u Švicarskoj, te je na tržištu predstavljena 2008. godine. Zaštitni je znak tvrtke Promo-Fruit Ltd (2019) koja promovira, distribuira i izdaje licencirane sadnice i plodove ove sorte poznate i pod nazivom 'Rafzaqu'. Nastala je križanjem američke sorte 'Autumn Bliss' (U.S. Plant Pat. No. 6,597) i 'Raftazer' (nije licencirana u SAD-u i prodaje se pod nazivom 'Himbo Queen'). Sortu 'Himbo Top' karakteriziraju veliki plodovi i otpornost prema Phytophtora fragariae var. rubi. Ima snažan rast i manji broj stolona. Cvjetovi su bijele boje i cvatu od travnja do svibnja. Plodovi su veličine 6 do $8 \mathrm{~g}$, svijetlo crvene boje. Dozrijevaju od srpnja do rujna, berba traje 6-8 tjedana. Od drugih sorata ima za oko 50\% veći prinos. Biljni materijal dopremljen je iz komercijalnog proizvodnog nasada proizvođača Fragaria d.o.o. u listopadu 2018. godine. Plodovi su prikupljeni u punoj fiziološkoj zrelosti. Zdravi, neoštećeni mladi i stariji listovi prikupljeni su s istih jedinki kao i plodovi. Zaprimljeni plodovi i listovi, čuvali su se u zamrzivaču na $-40{ }^{\circ} \mathrm{C}$ do početka kemijske analize. Sjemenke su ekstrahirane iz prikupljenih plodova.

\section{Priprema ekstrakata}

Uzorak od 5 g ploda maline usitnjen je u tarioniku te kvantitativno prenesen u Erlenmeyerovu tikvicu u koju je potom dodano $30 \mathrm{~mL} 50 \%$ vodene otopine etanola (\% v/v). Smjesa se promiješala te ostavila $24 \mathrm{~h} \mathrm{u}$ mraku i na sobnoj temperaturi. Nakon toga, smjesa se stavila $\mathrm{u}$ ultrazvučnu kupelj na 35 min pri $70{ }^{\circ} \mathrm{C}$. Ekstrakt je potom filtriran kroz filtar papir u odmjernu tikvicu od $50 \mathrm{~mL}$ te nadopunjen s ekstrakcijskim otapalom do oznake.

Uzorak od 2 g listova maline usitnjen je u tarioniku i kvantitativno prenesen u Erlenmeyerovu tikvicu u koju je potom dodano $30 \mathrm{~mL} 50 \%$ vodene otopine etanola (\% v/v). Nakon toga, smjesa se stavila u ultrazvučnu kupelj na 35 min pri $70{ }^{\circ} \mathrm{C}$. Ekstrakt je potom filtriran kroz filtar papir u odmjernu tikvicu od $50 \mathrm{~mL}$ te nadopunjen s ekstrakcijskim otapalom do oznake.

Sjemenke su iz plodova ekstrahirane pomoću miksera te su stavljene u $5 \%$ otopinu izbjeljivača na 30 min. Potom je 0,2 g sjemenki usitnjeno je u tarioniku i kvantitativno preneseno u Erlenmeyerovu tikvicu u koju je potom dodano $30 \mathrm{~mL}$ destilirane vode. Nakon toga, smjesa se stavila u ultrazvučnu kupelj na 35 min pri $70{ }^{\circ} \mathrm{C}$. Ekstrakt je potom filtriran kroz filtar papir $u$ odmjernu tikvicu od $50 \mathrm{~mL}$ te nadopunjen s ekstrakcijskim otapalom do oznake.

\section{Analitičke metode}

Ukupni fenoli, ukupni flavonoidi i flavan-3-oli određivani su prema Ivanova i sur. (2010). Antioksidacijski kapacitet određivani su pomoću DPPH (1,1-difenil-2-pikrilhidrazil) radikala prema Brand-Williams i sur. (1995) i ABTS (2,2'-azinobis (etilbenzotiazolin-6-sulfonske kiseline)) prema Re i sur. (1999).

Za identifikaciju pojedinačnih polifenola u ekstraktu ploda maline pomoću vezanog sustava tekućinska kromatografija visoke djelotvornosti-spektrometar masa (LC-MS) korišten je instrument Shimadzu Nexera X2-LCMS-8050. Pokretna faza A sastojala se od $1 \%$-tne otopine mravlje kiseline u vodi $(v / v)$, a pokretna faza B sastojala se od acetonitrila. Gradijentno eluiranje bilo je sljedeće: od 0 do 7 min, $30 \%$ B, od 7 do 27 min $50 \%$ B, od 27 do 30 min 33 \% B. Protok pokretne faze bio je $0,2 \mathrm{~mL} / \mathrm{min}$, a volumen injektirano uzorka bio je $10 \mu \mathrm{L}$. Korištena je kolona Shimpack XR ODS III $(1,6 \mu \mathrm{m}, 50 \times 2,0 \mathrm{~mm})$. Spektrometri masa dobiveni su u pozitivnom modu uz elektrosprej ionizaciju (engl. ESI-Electron Spray Ionization). 


\section{Statistička analiza}

Sve analize rađene su u triplikatu. Podaci istraživanja statistički su obrađeni u Excel programu (Microsoft Office, 2019) i programskom paketu SAS, verzija 9.3 (SAS, 2010). Srednje vrijednosti uspoređene su Tukey-evim testom, a smatraju se značajno različitima kod $p \leq 0,05$.

\section{Rezultati i rasprava}

Iz Tablice 1. vidljivo je kako su najvišu masenu koncentraciju flavonoida po gramu svježe tvari imale sjemenke maline, dok su najnižu imali plodovi maline.

Tablica 1. Maseni udjeli (mg/100 g svježe tvari) ukupnih fenola, ukupnih flavonoida, ukupnih antocijana te ukupnih flavan-3-ola u plodu, listu i sjemenci maline

Table 1. Mass fractions (mg/100 g of FW ) of total phenols, total flavonoids, total anthocyanins and total flavan-3-ols in fruit, leaf and raspberry seeds

\begin{tabular}{cccc}
\hline & Plod/Fruit & List/Leaf & Sjemenka/Seed \\
\hline $\begin{array}{c}\text { Ukupni fenoli } \\
\text { (mg GAE/100 g svježe tvari)/ } \\
\text { Total phenols (mg GAE/ } 100 \mathrm{~g} \mathrm{FW})\end{array}$ & $255,70^{\mathrm{c}} \pm 12,08$ & $848,89^{\mathrm{b}} \pm 77,73$ & $2369,44^{\mathrm{a}} \pm 138,6$ \\
\hline $\begin{array}{c}\text { Ukupni flavonoidi } \\
\text { mg QE/100 g svježe tvari/ }\end{array}$ & $142,81^{\mathrm{c}} \pm 13,64$ & $807,29^{\mathrm{b}} \pm 39,04$ & $2853,01^{\mathrm{a}} \pm 81,97$ \\
Total flavonoids (mg QE/100 g FW) & & & \\
\hline $\begin{array}{c}\text { Ukupni antocijani } \\
\text { (mg Cyn-3-glu eq/100 g } \\
\text { svježe tvari)/ }\end{array}$ & $38,74^{\mathrm{b}} \pm 2,10$ & n.d. & $105,5^{\mathrm{a}} \pm 1,5$ \\
$\begin{array}{c}\text { Total anthocyanins (mg Cyn-3-glu eq/100 } \\
\text { g FW) }\end{array}$ & & & \\
\hline $\begin{array}{c}\text { Ukupni flavan-3-oli } \\
\text { (mg CATeq/ 100 g svježe tvari)/ }\end{array}$ & $12,92^{\mathrm{b}} \pm 1,94$ & n.d. & $713,64^{\mathrm{a}} \pm 28,61$ \\
\hline
\end{tabular}

Prikazane srednje vrijednosti sa različitim slovima $u$ istom retku značajno se međusobno razlikuju prema Tukey-evom testu $(p<0,05) /$ Means with different letters in the same row are different according to Tukey test $(p<0,05)$, n.d. - nije detektirano/n.d.-not detected

Rezultati ANOVA-e pokazali su kako postoji značajna razlika u sadržaju polifenola u plodovima, sjemenci i listu. U listu maline maseni udio ukupnih fenola iznosio je 848,89 mg/100 g. Od svih analiziranih polifenola, utvrđen je najviši maseni udio flavonoida i ukupnih fenola kod svih analiziranih uzoraka. Najviše flavonoida imale su sjemenke maline 2853,03 mg/100 g svježeg uzorka, a list maline $807,29 \mathrm{mg} / 100 \mathrm{~g}$ svježeg uzorka, dok su plodovi maline imali $142,81 \mathrm{mg} / 100 \mathrm{~g}$ svježeg uzorka. Također, najviši maseni udio ukupnih fenola imale su sjemenke u iznosu 2369,44 mg/100 g svježeg uzorka. Utvrđeno je kako sjemenke sorte 'Himbo Top' imaju viši maseni udio ukupnih fenola od plodova sorte 'Heritage' (od 1208 do 1905 mg/100 g), te plodova sorata kupine 'Chester Thronless' (2008 mg/100 g), 'Thornless Evergreen' (2061 $\mathrm{mg} / 100 \mathrm{~g}$ ), te 'Hull Thornless' (2349 mg/100 g). U usporedbi s drugim sortama maline koje su imale maseni udio fenola u plodu od 274 do $714 \mathrm{mg} / 100 \mathrm{~g}$ svježe tvari, analizirani plod sorte Himbo Top ima značajno niži maseni udio ukupnih fenola (Bobinaite i sur., 2012). Ukupni fenoli u listovima maline iznosili su $8,5 \mathrm{mg} / \mathrm{g}$ svježe tvari $(848,89 \mathrm{mg} / 100 \mathrm{~g}$ svježe tvari) što je manje od drugih sorata maline ('Summit' 32,3 mg/g, 'Sentry' 11,8 mg/g, 'Canby' 16,9 mg/g i 'Autumn Bliss' 30,1 mg/g svježe tvari), kupine ('Chester Thronless' 20,7 mg/g, 'Hull Thornless' 18,5 mg/g svježe tvari) i jagode ('Allstar' 13,8 mg/g svježe tvari) (Wang i Lin, 2000). 
Od ukupnih flavan-3-ola sjemenke su imale viši maseni udio $(713,63 \mathrm{mg} / 100 \mathrm{~g}$ svježeg uzorka), u odnosu na plod maline koji je iznosio 12,91 mg/100 g svježeg uzroka (Slika 1). Prema Arts i sur. (2000) prosječne vrijednosti za katehin i epikatehin u plodu maline su 0,97 mg/100 g svježe tvari odnosno $0,83 \mathrm{mg} / 100 \mathrm{~g}$ svježe tvari.

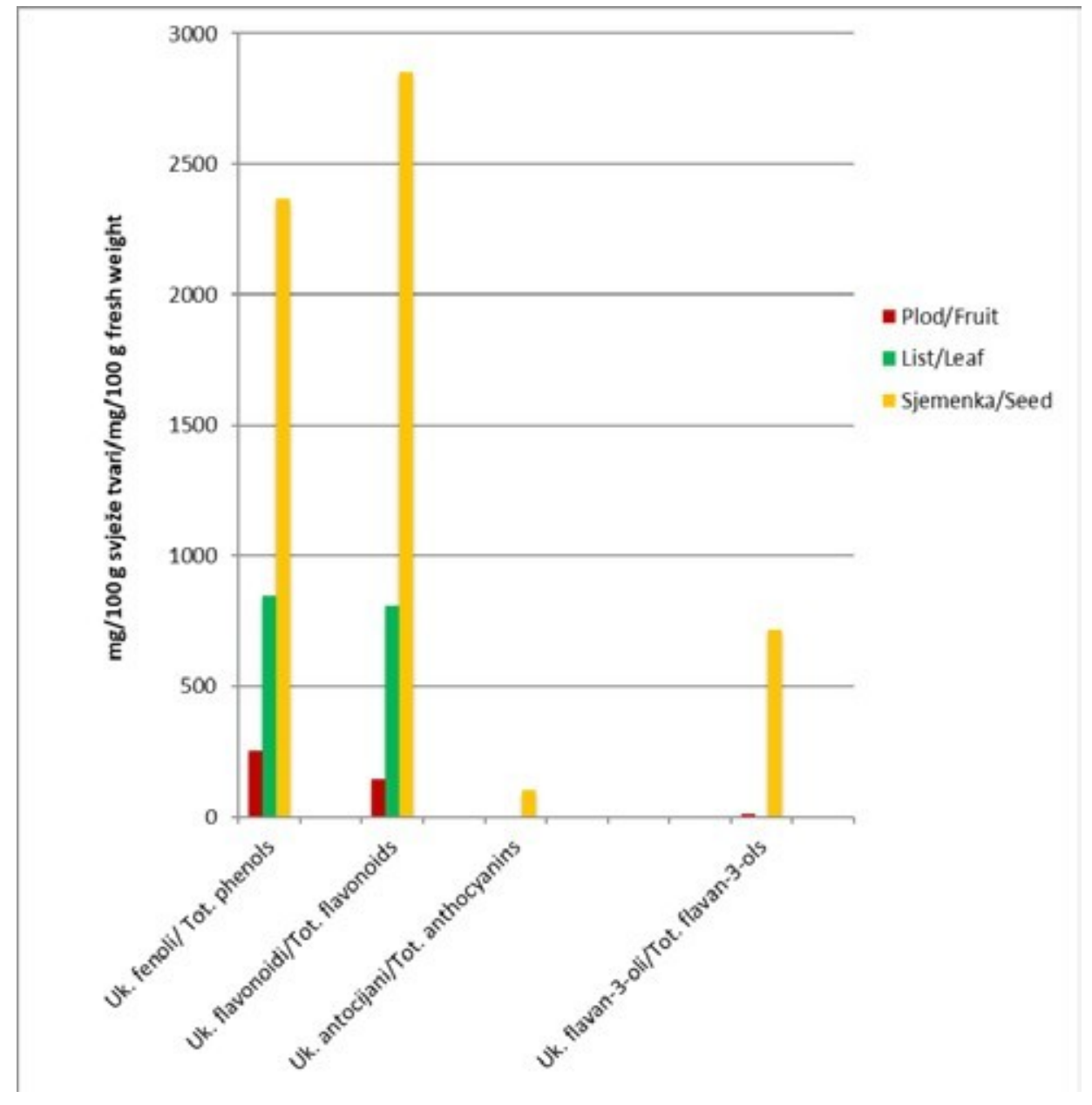

Slika 1. Sadržaj ukupnih fenola, flavonoida, antocijana i flavan-3-ola u plodu, listu i sjemenki maline sorte Himbo Top

Figure 1. Content of total phenols, flavonoids, anthocyanins and flavan-3-ols in the fruit, leaves and seeds of the raspberry variety Himbo Top

Od analiziranih polifenola najmanje je bilo antocijana, od kojih su sjemenke imale 105,5 $\mathrm{mg} / 100 \mathrm{~g}$ svježeg ploda, a plodovi su imali $38,74 \mathrm{mg} / 100 \mathrm{~g}$ svježeg uzorka. Maseni udio antocijana u plodu maline sorte Himbo Top $(38,74 \mathrm{mg} / 100 \mathrm{~g}$ svježe tvari) nije se značajno razlikovao od masenih udjela antocijana vodenih ekstrakata sorata 'Aksu Kirimizisi' (49,3 mg/100 g svježeg uzorka) i 'Hollanda Boduru' (45,6 mg/100 g svježeg uzorka) dok su više vrijednosti antocijana imale sorte 'Newburgh' (69,5 mg/100 g) i 'Rubin' (60,3 mg/100 g) (Sariburun, 2010). Također, 
sadržaj antocijana podudara se sa sadržajem antocijana roditeljske sorte 'Autumn Bliss'. Prema istraživanju Pantelidis i sur. (2010), sadržaj antocijana u sorti 'Autumn Bliss' bio je u rasponu od 35,1 do 39,1 mg/100 g svježeg uzorka. Sorta 'Himbo Top' ima značajno manji sadržaj antocijana u usporedbi sa sortama kupine 'Thornless Evergreen' (146,8 mg/100 g), 'Chester Thronless' $(134,6 \mathrm{mg} / 100 \mathrm{~g})$, 'Hull Thornless' $(152,2 \mathrm{mg} / 100 \mathrm{~g})$ te značajno više vrijednosti od žute sorte maline 'Fallgold' (od 1,3 do3,4 mg/100 g) (Pantelidis, 2010). U usporedbi sa križancima između crvene maline i kupine (Rubus idaeus x Rubus fruticosus) sorta 'Himbo Top' imala je značajno manji sadržaj antocijana u odnosu na križance 'Tayberry' (103,5 mg/100 g), 'Sunberry' (175,8 mg/100 g), 'Silvan' (197,8 mg/100 g). Više vrijednosti ukupnih antocijana kod križanaca između kupine i maline posljedica su genetskog utjecaja. Također, imala je značajno manji sadržaj antocijana u usporedbi sa sortama crvenog ribiza 'Rovada' (7,5 mg/100 g) i 'White Versailles' (1,4 mg/100 g). Nadalje, utvrđen je veći sadržaj antocijana u odnosu na jagodu (31,9 mg/100 g svježe tvari) (Wang i Lin, 2000). Različite vrijednosti antocijana između istraživanja posljedica su različitih analiziranih sorata te stupnja zrelosti (Jenić, M., 2019).

Tablica 2. Antioksidacijski kapacitet u plodu, listu i sjemenki maline sorte Himbo Top određeni pomoću DPPH i ABTS ( izraženi u $\mu$ mol Trolox/g svježeg uzorka)

Table 2. Antioxidant capacity in fruit, leaf and seeds of Himbo Top raspberry determined by DPPH and ABTS (in $\mu$ mol Trolox / g fresh weight)

\begin{tabular}{ccc}
\hline & DPPH & ABTS \\
\hline Plod/Fruit & $0,01 \pm 0$ & $0,01 \pm 0$ \\
\hline List/Leaf & $0,03 \pm 0,01$ & $0,04 \pm 0,01$ \\
\hline Sjemenka/Seed & $0,14 \pm 0,02$ & $0,12 \pm 0,03$ \\
\hline
\end{tabular}

U sorti 'Himbo Top' flavonoli su potvrđeni pomoću vezanog sustava tekućinska kromatografija visoke djelotvornosti-spektrometar masa (LC-MS) i to sljedeći spojevi: kvercetin-3-O-galaktozilramnozid, kempferol-3-O-glukozid, kempferol-3-O-rutinozid, kvercetin-3-O-glukozid, kvercetin-3-O-galaktozid, kvercetin-3-O-rutinozid. Određen je i antioksidacijski kapacitet pomoću DPPH i ABTS metode, te nisu utvrđene značajne razlike između ploda, lista i sjemenke (Tablica 2). Metodom DPPH utvrđeno je kako su sjemenke imale 0,14 $\mathrm{mmol} / \mathrm{g}$ svježeg uzorka antioksidacijski kapacitet, a listovi su imali $0,03 \mu \mathrm{mol} / \mathrm{g}$ svježeg uzorka, dok su plodovi imali najmanji antioksidacijski kapacitet $(0,01 \mu \mathrm{mol} / \mathrm{g}$ svježeg uzorka). Pomoću ABTS metode u sjemenkama je određeno 0,12 $\mu \mathrm{mol} / \mathrm{g}$ svježeg uzorka antioksidacijskog kapaciteta, u listovima $0,043 \mu \mathrm{mol} / \mathrm{g}$ svježeg uzorka, dok su plodovi imali najmanji antioksidacijski kapacitet 0,013 $\mu \mathrm{mol} / \mathrm{g}$ svježeg uzorka.

\section{Zaključak}

Rezultatima ovog rada utvrđeno je kako postoji značajna razlika u sadržaju polifenola u svim analiziranim uzorcima. Najveći maseni udio polifenola imale su sjemenke maline, od kojih je izmjereno najviše flavonoida (2853,03 mg/100 g svježeg uzorka) i ukupnih fenola (2369,44 $\mathrm{mg} / 100 \mathrm{~g}$ svježeg ploda), dok su listovi imali $807,01 \mathrm{mg} / 100 \mathrm{~g}$ svježe tvari flavonoida i 848,89 $\mathrm{mg} / 100 \mathrm{~g}$ svježe tvari ukupnih fenola. Najmanji maseni udio polifenola kod maline imali su plodovi, u usporedbi s listovima i sjemenkama. Nije utvrđena značajna razlika između antioksidacijskog kapaciteta u analiziranim uzorcima. Utvrđeno je kako su listovi i sjemenke bogatiji polifenolima nego plodovi maline te čine vrijedan alternativni prirodni izvor polifenola. Budući da su bioaktivni spojevi teško dostupni ljudima i u biljkama se nalaze u malim količinama po- 
trebna su daljnja istraživanja njihove biodostupnosti koja bi mogla dati novi pristup u medicini ili prehrambenoj industriji poput ekstrakcije i inkapsulacije bioaktivnih spojeva iz maline.

\title{
Napomena
}

Ovaj znanstveni rad napisan je na temelju rezultata diplomskog rada Milene Jenić pod naslovom Bioaktivne komponente u plodu, listu i sjemenci maline (Rubus idaeus L.). Zahvaljujemo tvrtki Shimadzu na ustupanju LC-MS instrumenta na korištenje!

\section{Literatura:}

Arts, I.C.W., Van den Putte, B., Hollman, P.C.H.(2000) Catechin Contents of Foods commonly consumed in the Nederlands 1. Fruits, Vegetables, Staple Foods and Processed Foods. Journal of Agricultural and Food Chemistry 48(5), 1746-1751. Beekwilder, J., Hall, R. D., Ric Vos, C. H. D. (2005) Identifi tion and dietary relevance of antioxidants from raspberry. BioFactors, 23(4), 197-205.

Bobinaite R., Viškelis P. Venskutonis, P. R. (2012) Variation of total phenolics, anthocyanins, ellagic acid and radical scavenging capacity in various raspberry (Rubus spp.) cultivars. Food Chemistry, 132, 1495-1501.

Brand-Williams, W., Cuvelier, M.E., Berset, C. (1995) Use of a free radical method to evaluate antioxidant activity. LWTFood and Science Technology, 28, 25-30.

FAO, FAOSTAT (2019)

Ivanova, V., Stefova, M., Chinnici, F. (2010) Determination of the polyphenol contents in Macedonian grapes and wines by standardized spectrophotometric methods. Journal of the Serbian Chemical Society, 75 (1), 45-59.

Jenić, M. (2019) Bioaktivne komponente u plodu, listu i sjemenci maline (Rubus idaeus L.). Diplomski rad, Sevučilište u Zagrebu, Agronomski fakultet.

Kratchanova, M., Denev, P., Ciz, M., Lojek, A., Mihailov, A. (2010) Evaluation of antioxidant activity of medicinal plants containing polyphenol compounds. Comparison of two extraction systems. Acta Biochimica Polonica, 57, $229-234$.

Nikolić D., Milivojević J. M. (2015) Jagodaste voćke - tehnologija gajenja, Beograd: Biograf d.o.o

Pantelidis, G., Vasilakakis, M., Manganaris, G., \& Diamantidis, G. (2007) Antioxidant capacity, phenol, anthocyanin and ascorbic acid contents in raspberries, blackberries, red currants, gooseberries and Cornelian cherries. Food Chemistry, 102(3), 777-783.

Sariburun, E., Şahin, S., Demir, C., Türkben, C., \& Uylaşer, V. (2010) Phenolic Content and Antioxidant Activity of Raspberry and Blackberry Cultivars. Journal of Food Science, 75(4), C328-C335.

Re, R., Pellegrini, N., Proteggente, A., Pannala, A., Yang, M., Rice-Evans, C. (1999) Antioxidant activity applying an improved ABTS radical cation decolorization assay. Free Radical Biology and Medicine, 26, 1231-1237.

Wang, S. Y., \& Lin, H.-S. (2000) Antioxidant Activity in Fruits and Leaves of Blackberry, Raspberry, and Strawberry Varies with Cultivar and Developmental Stage. Journal of Agricultural and Food Chemistry, 48(2), 140-146.

Žlabur, J. Š., Voća, S., Dobričević, N., Pliestić, S., Galić, A., Skendrović-Babojelić, M., \& Petrović, M. (2016) The usability potential of raspberry organic residue. In 5. Simpozij s međunarodnim sudjelovanjem Kopački rit jučer, danas, sutra 2016.

\section{Bioactive compounds in the fruit, leaves and seeds of raspberry (Rubus idaeus L.)}

\begin{abstract}
Raspberry (Rubus idaeus L.) is one of the fruit species that is rich in a variety of chemical compounds such as vitamins, minerals and polyphenols. Polyphenols affect the sensory and nutritional properties of the plant. Raspberry leaves and seeds, which are mostly a by-product of production, have a significant polyphenol content and, together with the fruits, could be used more in the human diet as an alternative source of bioactive compounds. In this work, polyphenolic compounds were determined, and the content of flavonoids, anthocyanins and total phenols in the fruit, seeds and leaves of raspberry cultivar 'Himbo Top' was determined. Raspberry seeds had the highest mass fraction of polyphenols, of which the most flavonoids (2853.03 mg / $100 \mathrm{~g}$ of fresh sample) and total phenols (2369.44 mg / $100 \mathrm{~g}$ of fresh fruit) were measured, and the lowest mass fraction of polyphenols in raspberries had fruits. Also, antioxidant capacity was determined using DPPH and ABTS methods, and no significant differences in antioxidant capacity were found between fruit, leaves and seeds. Using the LC-MS method, individual anthocyanins and flavonols in raspberryfruit were identified.

Keywords: Raspberry (Rubus idaeus L.), seed, leaf, polyphenols, antioxidant capacity
\end{abstract}

